eCommons@AKU

THE AGA KHAN UNIVERSITY

Department of Surgery

Section of Otolaryngology, Head \& Neck Surgery

Depatment of Surgery

November 2009

\title{
Adenoid cystic carcinoma of the external auditory canal
}

Mohammad Hussham Arshad

Aga Khan University

Umair Khalid

Aga Khan University

Shehzad Ghaffar

Aga Khan University

Follow this and additional works at: http://ecommons.aku.edu/

pakistan_fhs_mc_surg_otolaryngol_head_neck

Part of the Otolaryngology Commons

\section{Recommended Citation}

Arshad, M., Khalid, U., Ghaffar, S. (2009). Adenoid cystic carcinoma of the external auditory canal. Journal of the College of Physicians and Surgeons Pakistan, 19(11), 726-8.

Available at: http://ecommons.aku.edu/pakistan_fhs_mc_surg_otolaryngol_head_neck/3 


\title{
Adenoid Cystic Carcinoma of the External Auditory Canal
}

\author{
Mohammad Hussham Arshad1, Umair Khalid1 and Shehzad Ghaffar2
}

\begin{abstract}
This is a rare case of a young male with biopsy proven adenoid cystic carcinoma of the external auditory canal who underwent excision of the lesion with superficial parotidectomy sparing the facial nerve. Histopathology showed perineural invasion, which is a diagnostic hallmark of adenoid cystic carcinoma. Clinical examination, chest X-ray and CT scan showed no signs of recurrence or metastasis 2 years postoperatively.
\end{abstract}

Key words: Adenoid cystic carcinoma. External auditory canal. Ear carcinoma. Perineural invasion.

\section{INTRODUCTION}

Of the four types of tumours of ceruminous gland origin, adenoid cystic carcinoma (ACC) of the external auditory canal (EAC) is very rare. 1 Thus a small number of cases reported have precluded the possibility of a separate staging system and parameters for determining recurrence and metastasis in such tumors. It must be mentioned that the signs and symptoms of this tumour do not always correlate with the histopathologic diagnosis and subsequent clinical behavior of these tumours. Deep incisional biopsies need to be taken for the diagnosis because superficial biopsies can frequently miss such a lesion. ${ }^{2}$ Treatment consists of a wide surgical resection of the auditory canal and adjacent structures. Certain histological features of the tumour seem to relate to its recurrence, unresectability and death from the tumour itself. 3

This case report describes this rare tumour with perineural invasion in a young male.

\section{CASE REPORT}

A 32-year-old male presented with earache and progressively increasing nodular swelling of the right external auditory canal (EAC) for the last one and a half year. There was no history of otorrhea or bleeding from the canal. The patient complained about a sense of heaviness with decreased hearing on the right side for the last one year. There was a history of chewing "Manipuri" (locally available tobacco) for the last 8-10 years.

Physical examination revealed a hard nodular swelling in the antero-superior part of the external auditory canal

\footnotetext{
1 Medical Student, The Aga Khan University, Karachi.

2 Department of Otolaryngology, Head and Neck Surgery, The Aga Khan University, Karachi.

Correspondence: Dr. Shehzad Ghaffar, B-213, Block-10, Gulshan-e-Iqbal, Karachi.

E-mail: shehzad.ghaffar@aku.edu

Received September 15, 2008, accepted August 18, 2009.
}

with normal Rinne's test but lateralization of the Weber test to the right. In rest of the head and neck examination, he had a left deviated nasal septum (DNS) and bilaterally enlarged tonsils. There was no evidence of nodes in the neck. Examination of the parotid gland and facial nerve was unremarkable.

Preliminary investigations for this patient included biopsy of the nodular swelling that later proved to be adenoid cystic carcinoma and a chest $X$-ray, that was reported as normal. Pure tone audiogram was indicative of conductive hearing loss. MRI showed a $1 \times 1.8 \times 2$ cms tumour in the antero - superior part of the external auditory canal abutting the temporomandibular joint (TMJ).

Patient underwent excision of the auditory canal lesion with right superficial parotidectomy. Per-operative findings revealed a $1.8 \times 1.5 \mathrm{~cm}$ lesion involving the antero-superior part of the cartilaginous external auditory canal reaching up to TMJ but not involving it. Tumour was also reaching up to the lower end of temporalis muscle. Bony EAC underneath the tumour was irregular. Facial nerve was intact and far from the lesion.

The tumour was excised in toto with part of cartilaginous EAC where the tumour was extending. Superficial parotidectomy was done sparing the facial nerve, integrity of which was confirmed postoperatively. Histopathology indicated dermal invasion, with the neoplastic lesion exhibiting cribriform pattern with several small, round, pseudocystic structures filled with basophilic material. The majority of tumour cells were uniform in size and shape, with pale eosinophilic to amphophilic cytoplasm and poorly defined boundaries. The nuclei were uniform in size and very darkly basophilic with homogenous chromatin pattern. Some tumour cells showed perineural invasion which is a diagnostic hallmark of adenoid cystic carcinoma. Epidermis was not involved, with the lesion being $0.4 \mathrm{~cm}$ away from the skin (Figure 1). 


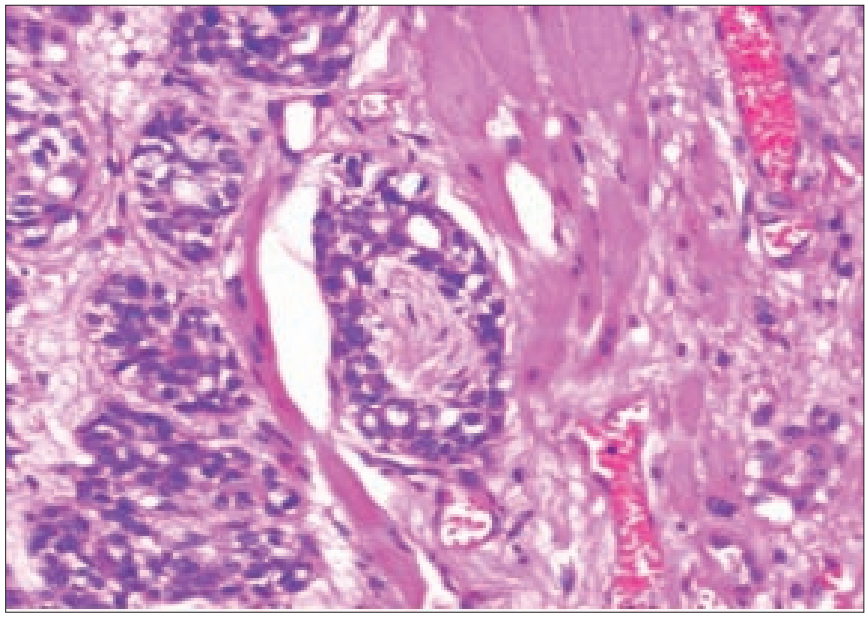

Figure 1: Adenoid cystic carcinoma with perineural invasion H\&E stain, 20X.

The patient had no complains postoperatively. He was advised postoperative radiation therapy and regular follow-up. He developed otitis externa secondary to radiation therapy which was treated accordingly. Last clinical examination, chest X-ray and CT scan repeated at 2 years postoperatively were unremarkable. To date, the patient has shown no signs of recurrence.

\section{DISCUSSION}

Adenoid cystic carcinoma of the external auditory canal (EAC), is a specific variant of adenocarcinoma and is extremely rare in EAC. These tumours are positive for cytokeratin and S-100 protein, which indicates ceruminous gland origin. The patients generally present with recurrent, longstanding, painful discharge and progressive conductive hearing loss due to the occluding mass in the EAC. There might also be subcutaneous induration in the external auditory canal. ${ }^{1,2}$

The natural course and clinical approach to EAC tumours can be determined by accurate histopathologic evaluation. A wide/deep incisional biopsy should be performed in every EAC lesion as it is imperative for the diagnosis of ACC in EAC. While reporting the biopsies from the external auditory canal, one should keep the adenoid cystic carcinoma as one of the possible differentials, especially if the biopsy is superficial, because its diagnosis is frequently missed. This rare neoplasm should also be considered in the differential diagnosis of poorly differentiated carcinomas metastatic to the central nervous system in patients with occult malignant neoplasm. $1,2,5$

On MRI, gadolinium-DTPA contrast is helpful is demonstrating infiltration into surrounding structures but is not useful in differentiating the three histological patterns because there is diffuse contrast enhancement in all types. Three main histological patterns of ACC have been described: tubular, cribriform and solid. Because of the small number of cases, significant correlation between histological patterns and clinical outcome could not be demonstrated. In salivary glands, tubular ACC has the best prognosis whereas solid ACC has the worst prognosis. In this patient, histopathologic evaluation of the resected mass confirmed it to be of cribriform subtype. ${ }^{1}$

Fine needle aspiration cytology for diagnosis is generally recommended which demonstrates the presence of hyaline globules surrounded by tumour cells. The tumour cells have uniform, round, hyperchromatic nuclei, visible nucleoli and little cytoplasm. A staging system has been proposed by the University of Pittsburgh for squamous cell carcinoma of the EAC. Currently, the same staging system is employed for ACC of EAC as well. There is a need for staging system for ACC of EAC.6,7

Treatment consists of a wide surgical resection of the auditory canal and adjacent structures. A study of 37 cases of adenoid cystic carcinoma treated between 1962 and 1979 showed that non-radical surgical treatment associated with radiotherapy seems to give results comparable to those obtained with radical surgery alone. Although ACCs have a relatively benign histological appearance and slow growth, repeated recurrences and distant metastases may occur over many years, but this course is highly variable as proven in studies.

This patient underwent non-radical surgery and had no recurrence as confirmed by the follow-up scans. Hence, non-radical surgery without radiotherapy is suggested for patients with ACC of EAC who do not have lymphatic spread or facial nerve or TMJ involvement.3,4,8-10

\section{REFERENCES}

1. Aikawa H, Tomonari K, Okino $\mathrm{Y}$, Hori F, Ueyama $\mathrm{T}$, Suenaga $\mathrm{S}$, et al. Adenoid cystic carcinoma of the external auditory canal: correlation between histological features and MRI appearances. Br J Radiol 1997; 70:530-2.

2. Garbyal RS, Kumar M, Bohra A. Adenoid cystic carcinoma of ceruminous gland: a case report. Indian J Pathol Microbiol 2006; 49:587-9.

3. Perzin KH, Gullane P, Conley J. Adenoid cystic carcinoma involving the external auditory canal. A clinicopathologic study of 16 cases. Cancer 1982 15; 50:2873-83.

4. Hicks GW. Tumours arising from the glandular structures of the external auditory canal. Laryngoscope 1983; 93:326-40.

5. Conlin PA, Mira JL, Graham SC, Kaye KS, Cordero J. Ceruminous gland adenoid cystic carcinoma with contralateral metastasis to the brain. Arch Pathol Lab Med 2002; 126:87-9. 
6. Mohan H, Handa U, Amanjit, Kotwal SA, Dass A. Adenoid cystic carcinoma of the external auditory canal. A case report with diagnosis by fine needle aspiration. Acta Cytol 2003; 47:792-4.

7. Nyrop M, Grøntved A. Cancer of the external auditory canal. Arch Otolaryngol Head Neck Surg 2002; 128:834-7.

8. Fliss DM, Kraus M, Tovi F. Adenoid cystic carcinoma of the external auditory canal. Ear Nose Throat J 1990; 69:635.

9. Dal Maso M, Lippi L. Adenoid cystic carcinoma of the head and neck: a clinical study of 37 cases. Laryngoscope 1985; 95:177-81.

10. Ahmed GM, Nath DK. Ceruminous gland tumour (a case report). J Laryngol Otol 1988; 102:346-9.

头.... 